\title{
Minyak Lavender dan Citrus Aurantium Dikombinasi Dengan Pijat Endorphin Efektif Dalam Meredakan Nyeri Ibu Bersalin di BPM Wilayah Kabupaten Simalungun
}

\author{
Sukaisi, Zuraidah \\ (Program Studi Kebidanan Pematangsiantar Poltekkes Kemenkes Medan) \\ Email: sukaisi.kes@gmail.com
}

\begin{abstract}
Labor pain is a subjective experience of physical sensations associated with uterine contractions, cervical dilatation and thinning, and fetal decline during labor. Labor pain is one of the causes of prolonged labor and fetal death. Old parturition contributes 5\% to the causes of maternal death in Indonesia.Aromatherapy using processed citrus Aurantium can reduce pain, fatigue, and anxiety in labor. Other complementary therapies that are non-pharmacological to relieve pain during labor are a massage. the first phase of active labor.This type of research is a quasi-experimental pre and posttest group with control design. conducted for 90 first-time mothers, aged 19-41 years at the Midwife Independent Practice in the Simalungun District, May - October 2019. The sampling technique was consecutive sampling according to inclusion criteria. Endorphine massage was performed using lavender and citrus Aurantium essential oils in the intervention group and the control group without treatment. Pain scale measurement with the Abbey scale is done early before the intervention and end of the first phase of the active phase. Data analysis uses the Kruskal Walis test using SPSS version 16.0.The results of this study obtained a significant difference between groups with a p-value of $<0.001$ with the average pain intensity at the end of the first phase of the active phase, namely moderate pain and intervention groups, namely mild pain. The pain intensity scale before and after the intervention obtained a significant effect from both intervention groups. Aromatic administration in the active phase I influence the duration of the first stage. The use of aromatic lavender oil and citrus Aurantium in maternity as an integrative therapy in obstetric care.

Keywords: endorphin massage, lavender oil, citrus aurantium oil, pain in the first stage of labor
\end{abstract}

\begin{abstract}
ABSTRAK
Nyeri persalinan merupakan pengalaman subjektif tentang sensasi fisik yang terkait dengan kontraksi uterus, dilatasi dan penipisan serviks, serta penurunan janin selama persalinan. Nyeri persalinan merupakan salah satu penyebab terjadinya partus lama dan kematian janin. Partus lama memberikan sumbangan 5\% terhadap penyebab kematian ibu di Indonesia. Aromaterapi dengan menggunakan olahan citrus aurentius dapat mengurangi rasa sakit, keletihan dan kecemasan dalam persalinan.Terapi komplementer lain yang non farmakologi untuk meredakan nyeri selama persalinan adalah pijatan.Tujuan penelitian adalah untuk mengetahui efektifitas minyak lavender dan citrus aurantium dikombinasikan dengan pijat endorphine terhadap skala intensitas nyeri kala I fase aktif persalinan. Jenis penelitian adalah quasi experiment pre and post test group with control design. dilakukan kepada 90 orang ibu bersalin kala I, usia 19-41 tahun di Praktek Mandiri Bidan di Wilayah Kabupaten Simalungun, Mei - Oktober 2019. Teknik pengambilan sampel adalah consecutive sampling sesuai dengan kriteria inklusi. Dilakukan pemijatan endorphine dengan menggunakan minyak essensial lavender dan citrus aurantium pada kelompok intervensi dan pada kelompok kontrol tanpa perlakuan. Pengukuran skala nyeri dengan Skala abbey dilakukan awal sebelum intervensi dan akhir kala I fase aktif. Analisa data menggunakan uji Kruskal Walis menggunakan SPSS versi 16.0.Hasil penelitian ini diperoleh adanya perbedaan yang signifikan antar kelompok dengan nilai $p$ value sebesar $<0.001$ dengan rerata intensitas nyeri pada akhir kala I fase aktif, yaitu nyeri sedang dan kelompok intervensi, yaitu nyeri ringan. Skala intensitas nyeri sebelum dan setelah intervensi diperoleh adanya pengaruh yang signifikan dari kedua kelompok intervensi. Pemberian aromatik pada kala I fase aktif mempengaruhi durasi kala I. Penggunaan aromatik minyak lavender dan citrus aurantium pada ibu bersalin sebagai terapi integratif dalam pelayanan kebidanan.
\end{abstract}

Kata kunci : pijat endorphine, minyak lavender, minyak citrus aurantium, nyeri kala I persalinan 


\section{PENDAHULUAN}

\section{Latar Belakang}

Persalinan merupakan suatu proses pengeluaran hasil konsepsi (janin dan plasenta) yang cukup bulan atau dapat hidup diluar kandungan melalui jalan lahir atau melalui jalan lain, dengan bantuan ataupun tanpa bantuan (kekuatan sendiri) ${ }^{(1)}$. Persalinan merupakan suatu peristiwa yang sangat penting dalam kehidupan wanita. Proses persalinan memiliki arti yang berbeda dengan adanya pengalaman akan memunculkan kecemasan dan ketakutan yang berlebih selama proses persalinan. Keadaan ini sering terjadi pada wanita yang pertama kali melahirkan ${ }^{(2)}$.

Nyeri persalinan merupakan pengalaman subjektif tentang sensasi fisik yang terkait dengan kontraksi uterus, dilatasi dan penipisan serviks, serta penurunan janin selama persalinan. Respon fisiologis terhadap nyeri meliputi peningkatan tekanan darah, denyut nadi, pernapasan, keringat, diameter pupil, dan ketegangan otot ${ }^{(3)}$. Rasa nyeri muncul akibat respon psikis dan refleks fisik. Rasa nyeri dalam persalinan menimbulkan gejala yang mudah dikenali. Peningkatan aktivitas sistem saraf simpatik timbul sebagai respon terhadap nyeri dan dapat mengakibatkan perubahan tekanan darah, denyut nadi, pernafasan, dan warna kulit. Perubahan afektif berupa rasa cemas disertai lapang perseptual yang menyempit, mengerang, menangis, gerak- antangan (yang menandakan rasa nyeri) dan ketegangan otot yang sangat diseluruh tubuh $^{(4)}$. Nyeri persalinan merupakan salah satu penyebab terjadinya partus lama dan kematian janin. Partus lama memberikan sumbangan 5\% terhadap penyebab kematian ibu di Indonesia.

Hasil penelitian mendapatkan ada perbedaan yang signifikan antara responden bersalin yang diberi aroma lavender dengan placebo.$^{(5)}$. Aroma lavender dapat mengurangi nyeri persalinan. Begitu juga dengan penelitian pemberian aromaterapi lavender mengurangi intensitas nyeri selama persalinan. ${ }^{(6)}$.. Namun penelitian lain menyebutkan bahwa tidak ada perbedaan antara responden yang diberi terapi konvensional yang diintervensi dengan chamomile, minyak jahe, lavender, serai dibanding respoden yang menerina perawatan standar. ${ }^{(7)}$. Penelitian Beigi ${ }^{(4)}$, memperoleh hasil aromaterapi dengan menggunakan lavender dan rose efektif untuk mengatasi kecemasan dalam proses persalinan.

Penelitian lain mendapatkan terapi komplementar dengan responden yang bersalin dengan pemberian minyak jeruk signifikan mengalami pengurangan rasa nyeri selama persalinan. ${ }^{(8)}$. Paparan yang lama minyak esens lemon signifikan mengurangi kecemasan dan nyeri pada tikus. ${ }^{(9)}$. Aromaterapi dengan menggunakan olahan citrus aurentius dapat mengurangi rasa sakit, keletihan dan kecemasan dalam persalinan ${ }^{(10)}$. Pijat endorphin merupakan sebuah terapi sentuhan atau pijatan ringan yang diberikan pada wanita hamil menjelang persalinan. Pijat endorphine pada persalinan mengurangi nyeri dan kecemasan. ${ }^{(11)}$..

Berdasarkan hal tersebut, peneliti tertarik untuk melakukan penelitian tentang perbandingan efektifitas pijat endhorphine dan aromatherapy lavender dan citrus aurantium terhadap intensitas nyeri persalinan kala I di Bidan Praktik mandiri wilayah Kabupaten Simalungun.

\section{Tujuan Penelitian}

a. Mengetahui karakteristik sampel penelitian.

b. Mengetahui skala intensitas nyeri ibu bersalin kala I yang diberi minyak lavender dan pijat endorphin.

c. Mengetahui skala intensitas nyeri ibu bersalin kala I yang diberi minyak citrus aurantium dan pijat endorphine

d. Mengetahui skala intensitas nyeri ibu bersalin kala I kelompok control

e. Membandingkan skala intensitas nyeri ibu bersalin kala I yang diberi minyak lavender dan aromatherapy citrus aurantium serta kelompok control

\section{Hipotesis}

Ada pengaruh intervensi minyak lavender dan citrus aurantium yang dikombinasi pijat endorphin terhadap skala intensitas nyeri ibu bersalin kala I dibandingkan kelompok kontrol.

\section{METODE}

Penelitian ini adalah penelitian analitik dengan rancangan quasi experiment. Pada penelitian ini membedakan intensitas nyeri kala I pada ibu bersalin yang mendapat perlakuan minyak lavender dan pijat endhorpine serta minyak citrus aurantium dan pijat endhorpine, dilaksanakan di BPM Wilayah Kabupaten Simalungun Tahun 2019.

Populasi dalam penelitian ini adalah semua ibu bersalin kala I fase aktif di BPM Kabupaten Simalungun yang sudah memiliki $M o U$ dengan Program Studi Kebidanan Pematangsiantar (5 BPM).

Penentuan sampel dilakukan secara random dengan kriteria inklusi yaitu : Usia kehamilan >37 minggu, Kehamilan tunggal, Presentasi kepala, Menyetujui dan menandatangani informed consent Sedangkan kriteria ekslusi adalah; Persalinan yang pertama, Memiliki resiko tinggi atau mengalami komplikasi dalam kehamilan, Memiliki riwayat penyakit berat, Tidak konsumsi analgetik 3 jam sebelum dan selama intervensi, Riwayat infertil, kecanduan rokok \& alcohol, Alergi minyak lavender/citrus aurantium (dilakukan test alergi dengan mengoleskan minyak esensial didaerah lengan dalam ibu bersalin).

Besar sampel keseluruhan dalam penelitian ini adalah 90 orang (30 sampel kelompok intervensi 1, 30 
sampel kelompok intervensi 2 dan 30 sampel kelompok kontrol).

Pada awal penelitian dilakukan penapisan kriteria untuk menentukan subyek adalah ibu bersalin normal yang memenuhi kriteria, inpartu kala I, selanjutnya penandatanganan informed consent. Kemudian dilakukan pengukuran skala nyeri dengan Abbey Pain, sebelum dan sesudah dilakukan perlakuan.

HASIL

Data hasil penelitian ini meliputi:

Tabel 1 Karakteristik Responden Penelitian Efektifitas Minyak Lavender dan Citrus Aurantium Dikombinasikan dengan Pijat Endorphin dalam Meredakan Nyeri pada Ibu Bersalin di Praktek Bidan Mandiri Kabupaten Simalungun

\begin{tabular}{|c|c|c|c|}
\hline Variabel & $\begin{array}{c}\text { Kelompok } \\
\text { Kontrol }\end{array}$ & $\begin{array}{c}\text { Pijat endorfin } \\
+ \\
\text { minyak } \\
\text { lavender }\end{array}$ & $\begin{array}{c}\text { Pijat } \\
\text { endorpfin + } \\
\text { minyak } \\
\text { citrus } \\
\text { aurantium }\end{array}$ \\
\hline $\begin{array}{l}\text { Umur (tahun) } \\
\text { - } \text { Rerata(simpang } \\
\text { baku) } \\
\text { - Median (min- } \\
\text { mak) } \\
\end{array}$ & $\begin{array}{c}29,63(5,43) \\
28,50(22-40)\end{array}$ & $\begin{array}{c}28,67(5,34) \\
27,00(21-39)\end{array}$ & $\begin{array}{c}27,97(5,65) \\
27,00(19-41)\end{array}$ \\
\hline $\begin{array}{l}\text { Paritas } \\
-1(\%) \\
-2(\%) \\
-\quad 3(\%) \\
\end{array}$ & $\begin{array}{c}16(53,3) \\
10(33,3) \\
4(13,3) \\
\end{array}$ & $\begin{array}{c}15(50,0) \\
10(33,3) \\
5(16,7) \\
\end{array}$ & $\begin{array}{c}16(53,3) \\
11(36,7) \\
3(10,0) \\
\end{array}$ \\
\hline $\begin{array}{c}\text { Abortus } \\
-\quad 0(\%) \\
-\quad 1(\%) \\
\end{array}$ & $\begin{array}{c}25(83,3) \\
5(16,7) \\
\end{array}$ & $\begin{array}{c}26(86,7) \\
4(13,3) \\
\end{array}$ & $\begin{array}{c}27(90,0) \\
3(10,0) \\
\end{array}$ \\
\hline $\begin{array}{l}\text { Pembukaan } \\
\text { serviks } \\
\text { - Rerata } \\
\text { (simpang baku) } \\
\text { - Median (min- } \\
\text { mak) } \\
\end{array}$ & $\begin{array}{c}5,27(0,94) \\
5(4-8)\end{array}$ & $\begin{array}{c}4,90(0,88) \\
5(4-7)\end{array}$ & $\begin{array}{c}5,47(0,97) \\
5(4-8)\end{array}$ \\
\hline $\begin{array}{l}\text { Lama Kala I } \\
\text { (menit) } \\
\text { - } \text { Rerata } \\
\quad \text { (simpang baku) } \\
\text { - } \text { Median (min- } \\
\quad \text { mak) } \\
\end{array}$ & $\begin{array}{c}254,67 \\
(50,56) \\
245(180- \\
360) \\
\end{array}$ & $\begin{array}{c}208,33(47,85) \\
180(180-360)\end{array}$ & $\begin{array}{c}246(55,18) \\
240(150- \\
360)\end{array}$ \\
\hline $\begin{array}{l}\text { Lama Kala II } \\
\text { (menit) } \\
\text { - Rerata } \\
\text { (simpang baku) } \\
\text { - Median (min- } \\
\text { mak) }\end{array}$ & $\begin{array}{l}91,50(11,60) \\
90(70-115)\end{array}$ & $\begin{array}{l}62,83(20,83) \\
60(30-110)\end{array}$ & $\begin{array}{c}68,67(12,47) \\
70(50-110)\end{array}$ \\
\hline $\begin{array}{l}\text { Skala intensitas } \\
\text { nyeri sebelum } \\
\text { intervensi } \\
-\quad \text { Rerata } \\
\quad \text { (simpang } \\
\text { baku) } \\
\text { - Median } \\
\quad \text { (min-mak) }\end{array}$ & $\begin{array}{l}12,67(1,77) \\
12(10-17)\end{array}$ & $13,13(1,63)$ & $\begin{array}{l}12,17(1,29) \\
12(10-14)\end{array}$ \\
\hline
\end{tabular}

Berdasarkan tabel 1 diperoleh data usia responden pada kelompok kontrol rerata 29,63; pada kelompok pijatan endorphin dan minyak lavender usia rerata 28,67 ; sedang pada kelompok pijatan endorfin dan minyak citrus aurantium usia rerata 27,97. Untuk gravida umumnya pada semua kelompok adalah gravida kedua. Data paritas rerata yaitu pada kelompok kontrol sebesar 1,60; pada kelompok pijatan endorphin dan minyak lavender citrus sebesar 1,67; pada kelompok pijatan endorphin dan miyak citrus aurantium sebesar 1,57. Umumnya responden tidak mengalami abortus. Pembukaan serviks pada seluruh kelompok adalah pada pembukaan 4. Lama kala I persalinan diperoleh rerata pada kelompok kontrol adalah 254 menit, pada kelompok pijatan endorphin dan minyak lavender rerata lama kala I adalah 208 menit; sedang pada kelompok pijatan endorphin dan minyak citrus aurantium rerata kala I adalah 246 menit. Lama kala II pada kelompok kontrol adalah rerata 91,50 menit, pada kelompok pijatan endorfin dan minyak lavender rerata kala II adalah 62,83 menit; sedang pada kelompok pijatan endorphin dan minyak citrus aurantium rerata kala II adalah 68,67 menit. Data intensitas nyeri sebelum intervensi pada kelompok kontrol dan kelompok pijatan endorfin dan minyak citrus aurantium rerata skala 12; pada kelompok pijatan endorphin dan minyak lavender rerata nyeri sebelum intervensi adalah skala 13

Tabel 2 Perbedaan Lama kala I fase aktif pada ketiga kelompok

\begin{tabular}{|c|c|c|c|c|c|c|}
\hline $\begin{array}{l}\text { Varia } \\
\text { bel }\end{array}$ & Kelompok & $\mathrm{n}$ & $\begin{array}{c}\text { Mean } \\
\text { rank }\end{array}$ & $\begin{array}{c}\text { Median } \\
\text { (min-maks) }\end{array}$ & $\begin{array}{c}\text { Rerata } \\
\text { (simpa } \\
\text { ng } \\
\text { baku) }\end{array}$ & $P^{*}$ \\
\hline \multirow{3}{*}{$\begin{array}{l}\text { Lama } \\
\text { kala I } \\
(\text { meni } \\
\text { t) }\end{array}$} & $\begin{array}{l}\text { Kelompok } \\
\text { kontrol }\end{array}$ & 30 & 55,47 & $\begin{array}{c}245 \\
(180-360)\end{array}$ & $\begin{array}{l}254,67 \\
(50,56)\end{array}$ & $\begin{array}{c}< \\
0.00\end{array}$ \\
\hline & $\begin{array}{l}\text { Pijat endorfin } \\
\text { dan minyak } \\
\text { Lavender }\end{array}$ & 30 & 30,48 & $\begin{array}{c}180 \\
(180-360)\end{array}$ & $\begin{array}{l}208,33 \\
(47,85)\end{array}$ & \\
\hline & $\begin{array}{l}\text { Pijat endorfin } \\
\text { dan minyak } \\
\text { citrus } \\
\text { aurantium }\end{array}$ & 30 & 50,55 & $\begin{array}{c}240 \\
(150-360)\end{array}$ & $\begin{array}{c}246 \\
(55,18)\end{array}$ & \\
\hline
\end{tabular}

Berdasarkan tabel 2 di atas ditemukan perbedaan lama kala I fase aktif pada ketiga kelompok yaitu adanya perbedaan yang signifikan lama kala I fase aktif pada ketiga kelompok dengan nilai $\mathrm{p}$ value $<0.001$ dengan rerata lama kala I fase aktif pada kelompok kontrol 254,67 $(50,56)$ menit, pada kelompok pijatan endorphin dan minyak lavender, yaitu 208,33 (47,85) menit, dan pada kelompok pijatan endorphin dan minyak citrus auratium, yaitu $246(55,18)$ menit.
Tabel 3 Perbedaan skala intensitas nyeri sebelum dan setelah intervensi pada masing masing kelompok 


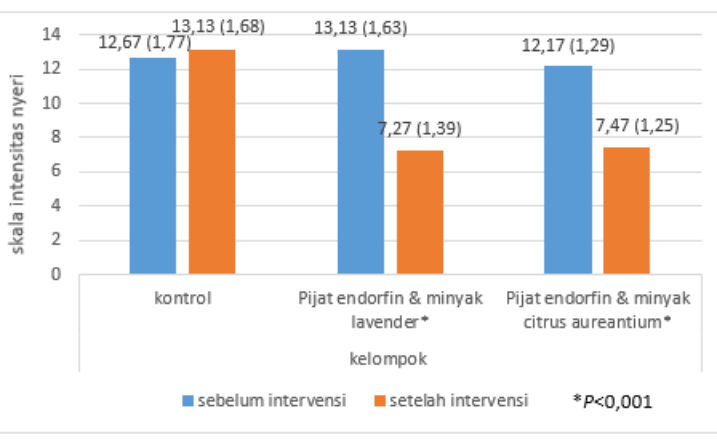

Berdasarkan tabel 3 di atas diperoleh pada kelompok kontrol saat sebelum intervensi skala nyeri didapat 12 dan akhir kala I fase aktif intensitas nyeri diperoleh skala 13. Pada kelompok pijatan endorphin dan minyak lavender serta kelompok pijatan endorphin dan minyak citrus aurantium sebelum intervensi intensitas nyeri skala 12 dan setelah intervensi skala 7

Tabel 4 Perbedaan skala intensitas nyeri kala I persalinan setelah intervensi pada ketiga kelompok

\begin{tabular}{|c|c|c|c|c|c|c|}
\hline $\begin{array}{l}\text { Variab } \\
\text { el }\end{array}$ & Kelompok & $\mathbf{N}$ & $\begin{array}{c}\text { Mean } \\
\text { rank }\end{array}$ & $\begin{array}{c}\text { Media } \\
\text { n } \\
\text { (min- } \\
\text { mak) }\end{array}$ & $\begin{array}{c}\text { Rerata } \\
\text { (simpa } \\
\text { ng } \\
\text { baku) }\end{array}$ & $P^{*}$ \\
\hline \multirow{3}{*}{$\begin{array}{c}\text { Skala } \\
\text { intensit } \\
\text { as nyeri } \\
\text { kala I }\end{array}$} & $\begin{array}{l}\text { Kelompok } \\
\text { kontrol }\end{array}$ & 30 & 75,42 & $\begin{array}{c}13(11- \\
17)\end{array}$ & $\begin{array}{l}13,13 \\
(1,67)\end{array}$ & $\begin{array}{l}< \\
0 . \\
00 \\
1\end{array}$ \\
\hline & $\begin{array}{l}\text { Pijat } \\
\text { endorfin } \\
\text { dan minyak } \\
\text { Lavender }\end{array}$ & 30 & 28,52 & $\begin{array}{c}7(6- \\
10)\end{array}$ & $\begin{array}{c}7,27 \\
(1,39)\end{array}$ & \\
\hline & $\begin{array}{l}\text { Pijat } \\
\text { endorfin } \\
\text { dan minyak } \\
\text { citrus } \\
\text { aurantium }\end{array}$ & 30 & 32,57 & $\begin{array}{c}7(6- \\
11)\end{array}$ & $\begin{array}{c}7,47 \\
(1,25)\end{array}$ & \\
\hline
\end{tabular}

Berdasarkan tabel diatas diperoleh data perbedaan skala intensitas nyeri kala I persalinan setelah diberi intervensi adalah adanya perbedaan yang signifikan antar kelompok dengan nilai $p$ value sebesar $<0.001$ dengan rerata skala intensitas nyeri setelah intervensi pada kelompok kontrol yaitu 13; pada kelompok pijatan endorphin dan minyak lavender dan kelompok pijatan endorphin dan minyak citrus aurantium nilai median 7

\section{PEMBAHASAN}

Nyeri persalinan merupakan keluhan umum ibu bersalin. Pengalaman melahirkan tiap wanita merupakan pengalaman kompleks dan subjektif. Banyak faktor yang mempengaruhi persepsi wanita tentang persalinan yang membuat menjadi unik. Sebagai temuan yang konsisten, nyeri persalinan berada pada peringkat tinggi skala nyeri bila dibanding dengan pengalaman hidup menyakitkan lainnya. ${ }^{(12)}$. Mengatasi nyeri persalinan secara efektif dan aman merupakan tantangan pelayanan kesehatan saat ini.
Penelitian ini mengukur intensitas nyeri ibu bersalin kala I setelah diberi intervensi berupa pijatan endorphin dan pemberian aromaterapi, yaitu minyak lavender dan minyak citrus aurantium untuk mengurangi nyeri persalinan.

Berdasarkan tabel 1 diperoleh secara umum usia responden dalam penelitian ini adalah masih periode usia reproduksi. Kondisi kehamilan responden mayoritas kehamilan kedua dan persalinan pertama, baik pada kelompok kontrol, kelompok pijatan endorphin dan minyak lavender, dan kelompok pijatan endorphin dan minyak citrus aurantium. Tidak diikutkan responden dengan kehamilan pertama karena kurangnya pemahaman dan pengalaman tentang proses persalinan, primipara lebih cenderung kekhawatiran menjalani proses persalinan dibanding multipara ${ }^{(13)}$. Responden pada penelitian ini umumnya tidak mempunyai riwayat abortus.

Intervensi dalam penelitian ini dilakukan pada ibu bersalin kala I fase aktif, yaitu fase dimana pembukaan serviks uterus berdiameter $4 \mathrm{~cm}$ atau lebih. Keseluruhan responden yang menjadi sampel penelitian ini, mulai dilakukan pengukuran nyeri pada pembukaan serviks $4 \mathrm{~cm}$. Tidak dilakukan pengukuran $<4 \mathrm{~cm}$ karena intensitas nyeri persalinan meningkat dengan dilatasi serviks yang lebih besar dan berkorelasi dengan baik dengan intensitas, durasi, dan frekuensi kontraksi uterus. ${ }^{(12)}$..

Berdasarkan tabel 4 ditemukan lama kala I terlama pada kelompok kontrol dan hampir serupa pada kelompok pijatan endorphin dan minyak citrus aurantium. Pada kelompok pijatan endorfin dan minyak lavender lama kala I lebih pendek dibanding kedua kelompok lain. Idealnya lama kala I fase aktif persalinan berlangsung sekitar 6 jam pada primipara dan setengahnya pada multipara ${ }^{(14)}$..

Lama kala II persalinan pada kelompok kontrol merupakan waktu terlama. Pada kelompok pijatan endorphin dan minyak lavender serta kelompok pijatan endorphin dan minyak citrus aurantium masih dalam batas wajar. Lama kala II persalinan yang bukan primipara adalah tidak melebihi 60 menit ${ }^{(14)}$.. Skala intensitas nyeri sebelum intervensi pada ketiga kelompok berada pada nyeri sedang (moderate pain). Pengukuran nyeri pada penelitian ini menggunakan skala Abbey. Skala abbey digunakan sebagai penilaian berbasis gerakan ${ }^{(15)}$.

Berdasarkan tabel 2 di atas diperoleh adanya perbedaan yang signifikan pada lama kala I ketiga kelompok responden. Ada pengaruh intervensi terhadap lama kala I fase aktif pada kelompok pijatan endorphin dan minyak lavender dan kelompok pijatan endorphin dan minyak citrus aurantium dibanding kelompok kontrol. Berbeda dengan penelitian (5), berupa pemberian aromaterapi lavender inhalasi mendapatkan tidak ada perbedaan durasi kala I fase aktif persalinan namun berpengaruh terhadap nyeri persalinan.

Lama kala I fase aktif pada primipara adalah sekitar 6 jam, pada multipara separuhnya. Hasil 
penelitian ini diperoleh lama kala I fase aktif pada kelompok kontrol dan kelompok pijatan endorphin dan minyak citrus aurantium sekitar 4 jam, pada kelompok pijatan endorphin dan minyak lavender sekitar 3 jam. Kedua hasil ini masih dalam batas normal. Pengukuran lama kala I penelitian ini dimulai awal fase aktif kala I sampai dilatasi serviks lengkap.

Penelitian Zahra ${ }^{(16)}$ pada responden primipara dan multipara dengan aromatik lavender dan pijatan diperoleh adanya pengaruh yang signifikan pada dilatasi serviks, namun tidak semua dilatasi serviks. Penelitian Vakilian dalam Makvandi (17). dengan responden multipara ditemukan tidak signifikan pada dilatasi serviks namun berpengaruh terhadap nyeri persalinan. Pada skala intensitas nyeri sebelum dan setelah intervensi diperoleh adanya pengaruh yang signifikan dari kedua kelompok intervensi. Ada pengaruh intervensi aromaterapi dan pijatan terhadap skala intensitas nyeri pada kelompok pijatan endorphin dan minyak lavender serta kelompok pijatan endorphin dan minyak citrus aurantium dibanding kelompok yang tidak diintervensi.

Penelitian Levett (18) mendapatkan bahwa terapi komplementer dapat mengurangi nyeri persalinan dan secara signifikan mengurangi penggunaan epidural dan operasi caesar. Terapi komplementer pada penelitian Levett ini dengan berbagai ragam, yaitu akupresure, visualisasi dan relaksasi, olah pernafasan, terapi pijat, yoga, dan fasilitas pendamping. Tournaire (19) mendapatkan bahwa terapi komplementer berupa aromaterapi, terapi pijat membantu mengatasi nyeri persalinan.

Penelitian Kaviani pada penggunaan minyak lavender dan pijatan punggung pada primipara mengurangi persepsi nyeri namun ini tidak berpengaruh pada dilatasi serviks ${ }^{(6)}$. Penelitian ini intervensi yang dilakukan berupa pijatan dengan minyak aromatik setelah kontraksi uterus (his persalinan). Durasi pijatan dilakukan sekitar 5 menit dan diulang kembali saat tidak ada kontraksi. Pengukuran nyeri dilakukan sebelum intervensi dan saat berakhir kala I.

Berdasarkan tabel 4 terdapat perbedaan dari Uji Kruskal-Wallis. Uji Post-hoc Mann Whitney U: Kelompok kontrol vs Pijat endorphin dan minyak lavender $=0,000$; Kelompok kontrol vs Pijat endorfin dan minyak citrus aurantium $=0,000$; Pijat endorfin dan minyak lavender vs Pijat endorphin dan minyak citrus aurantium $=0,361$. Skala intensitas nyeri pada kelompok kontrol vs Pijat endorphin dan antara kelompok kontrol vs Pijat endorphin dan minyak citrus aurantium hasilnya signifikan, namun dari skala intensitas nyeri pada kelompok Pijat endorfin dan minyak lavender vs Pijat endorphin dan minyak citrus aurantium mendapatkan hasil yang tidak signifikan.

Penelitian Levett mendapatkan bahwa terapi komplementer dapat mengurangi nyeri persalinan dan secara signifikan mengurangi penggunaan epidural dan operasi caesar. Terapi komplementer pada penelitian Levett ini dengan berbagai ragam, yaitu akupresure, visualisasi dan relaksasi, olah pernafasan, terapi pijat, yoga, dan fasilitas pendamping ${ }^{(18)}$. Penelitian review Tournaire (19) mendapatkan bahwa terapi komplementer berupa aromaterapi, terapi pijat membantu mengatasi nyeri persalinan.

Penelitian lain pada penggunaan minyak lavender dan pijatan punggung pada primipara mengurangi persepsi nyeri namun ini tidak berpengaruh pada dilatasi serviks ${ }^{(5)}$. Pada penelitian ini intervensi yang dilakukan berupa pijatan dengan minyak aromatik setelah kontraksi uterus (his persalinan). Durasi pijatan dilakukan sekitar 5 menit dan diulang kembali 15 menit kemudian saat tidak ada kontraksi his. Pengukuran nyeri dilakukan sebelum intervensi dan saat berakhir kala I.

Pemberian minyak lavender dan citrus aurantium telah dipercaya untuk mereda nyeri pada berbagai kondisi. Pada penelitian ini, baik pemberian minyak lavender maupun minyak citrus aurantium sama-sama signifikan dalam meredakan nyeri persalinan kala I. Pemberian minyak lavender dalam meredakan nyeri pada persalinan. ${ }^{(6)}{ }^{(20)}$ baik dengan pijatan maupun inhalasi cukup berhasil. Begitu pula pemberian minyak citrus aurantium pada persalinan.).

Penggunaan minyak lavender dan citrus aurantium tidak hanya untuk nyeri saja termasuk menurunkan kecemasan. Pada penelitian Bakhsha pada remaja diperoleh pemberian minyak lavender dan pemberian minyak citrus aurantium sama-sama signifikan menurunkan kecemasan pada remaja. ${ }^{(21)}$ Berbeda dengan penelitian Eslami dengan responden penelitian pasien pra operasi pengangkatan empedu di Iran. Diperoleh ada perbedaan yang signifikan antara kelompok yang diintervensi dengan minyak lavender dan citrus dengan kelompok kontrol (tanpa intervensi) ${ }^{(22)}$. Minyak lavender dan citrus aurantium menurunkan kecemasan pra operasi pengangkatan empedu. Namun antara minyak lavender dan citrus aurantium tidak berbeda secara signifikan dalam meredakan kecemasan.

\section{KESIMPULAN}

1. Penggunaan aromatik minyak lavender dan citrus aurantium mengurangi nyeri persalinan.

2. Pijat endorphin dengan menggunakan minyak lavender dan citrus aurantium membantu mempercepat masa kala I persalinan.

\section{SARAN}

1. Penggunaan aromatik minyak lavender dan citrus aurantium pada ibu bersalin sebagai terapi integratif dalam pelayanan kebidanan.

2. Penelitian selanjutnya penggunaan pijat endorphine kombinasi aromatik dilakukan pada ibu bersalin sejak Kala I fase Laten 


\section{DAFTAR PUSTAKA}

1. Sulistyowati A\& Nugraheny E, Asuhan Kebidanan pada Ibu bersalin, Jakarta Salemba Medika, 2013

2. Wijaya, D. E., Rillyani, Wandini, R., \& Wardiyah, A. Pengaruh Pendampingan Suami Terhadap Lamanya Persalinan Kala II di Ruang Delima RSUD DR.H. Abdul Moeloek Lampung. Jurnal Keperawatan, 2015, 6, 6

3. Arifin, Zainal dan Juniayah. 2008. Sintaksis. Jakarta: PT Grasindo

4. Beigi Nastaran Mohammad Ali, Broumandfar Khadijeh, Bahadoran Parvin, Abedi Heidar, Women's experience of pain during childbirth, Iran J Nurs Midwifery Res. 2010 Spring; 15(2): 77-82.

5. Yazdkhasti M, Pirak A, The Effect Of Aromatherapy With Lavender Essence On Severity Of Labor Pain And Duration Of Labor In Primiparous Women, Complement Therap Cli Pract, 2016; 25: 81-86.

6. Kaviani M., Azima S., Alavi N \& Tobei M.H., The effect of lavender aromatherapy on pain perception and intrapartum outcome in primiparous women, 2014; British Journal of Midwifery: 22 (2): 125-128.

7. Smith C. A., Collins C. T., \& Crowther C. A., Aromatherapy for pain management in labour, 2011; Cochrane Database of Systematic Reviews: $6(7)$.

8. Namazi, Amir Ali Akbari S, Mojab F, Talebi A, Alavi Majd H, Jannesari S, Aromatherapy with citrus aurantium oil and anxiety during the first stage of labor; 2014: Iran Red Crescent Med J.:16 (6).

9. Ceccarelli, I.; Lariviere, W.R.; Fiorenzani, P.; Sacerdote, P.; Aloisi, A.M. Effects of long-term exposure of lemon essential oil odor on behavioral, hormonal and neuronal parameters in male and female rats; 2004: Brain Res: 1001: 78-86

10. Fakari, F R,Hamed Mortazavi, Mahbubeh Tabatabaeichehr, The effect of aromatherapy by essential oil of orange on anxiety during labor: A randomized clinical trial, Iranian journal of nursing and midwifery research 20(6):661 - November 2015

11. Chang, C.C., Yang., M.H., Wem, H.M., Chern, J.C., 2002, Estimation of Total Flavonoid Content in Propolis by Two Complementary Colorimetric Methods, Journal of Food and Drug Analysis, Vol. 10, No.3, 2002. Pages 178-182.

12. Labor S, Maguire S, The Pain of Labour, 2008; Rev Pain. 2(2): 15-19.

13. Ou Youliang, Zhou Yanli, Xiang Ping, Effect Obstetric Fine Nursing on Pain during Natural Childbirth and Postpartum Recovery, Iran J Publish Health, 2018; 11 (47): 17031708.

14. WHO, WHO recommendations Intrapartum care for a positive childbirth experience, 2018.
15. Abbey J, De Bells A, Piller N, Esterman N, Giles L, Parker D, Lowcay B, Abbey Pain, 2002.

16. Zahra Abbaspoor, Leila Mohammadkhani Shahri, Lavender aromatherapy massages in reducing labor pain and duration of labor: A randomized controlled trial, African Journal of Pharmacy and Pharmacology; 2013: 7(8), pp. 426-430

17. Makvandi Somayeh, Mirzaiinajma Khadigeh, Mirteimoori Masoumeh, Sadeghi Ramin, An Update on the Effect of Massage and Inhalation Aromatherapy with Lavender on Labor Pain Relief: A Systematic Review and Meta-analysis, Journal of Obstetrics, Gynecology and Cancer Research, 2018; 3(1):29-37.

18. Levett Kate M, Smith CA, Bensoussan A, Dahlen HG, Complementary therapies for labour and birth study: a randomised controlled trial of antenatal integrative medicine for pain management in labour, BMJ, 2016; 6.

19. Tournaire M. \& Theau-Yonneau A, Complementary and alternative approach to pain relief during labor, 2007; Evid Based Complement Alternat Med:4(4): 409-17

20. Abbaspoor Z, Mohammadkhani Shahri L. Lavender aromatherapy massages in reducing labor pain and duration of labor: A randomized controlled trial. Afr J Pharm Pharmacol. 2013;7(8):426-30.

21. Bakhsha Fozieh, Yousefi Zahra, Aryaee Mohammad, Jafari Seyyed Yaquob, Derakhshanpoor Firoozeh, Comparison effect of Lavender and Citrus aurantium aroma on anxiety in female students at Golestan University of Medical Sciences, J Bas Res Med Sci 2016; 3(4):4-11.

22. Eslami Jamshid, Ebrahimi Abed, Hosseinkhani Ayda, Khazaei Zaher, Darvishi Isan, The effect of aromatherapy using Lavender (Lavandula angustifolia Miller) and Citrus aurantium L.extracts to treat anxiety of patients undergoing laparoscopic cholecystectomy: A randomized clinical trial in Iran, Biomed Res Ther: 2018, 5(3): 20962110 